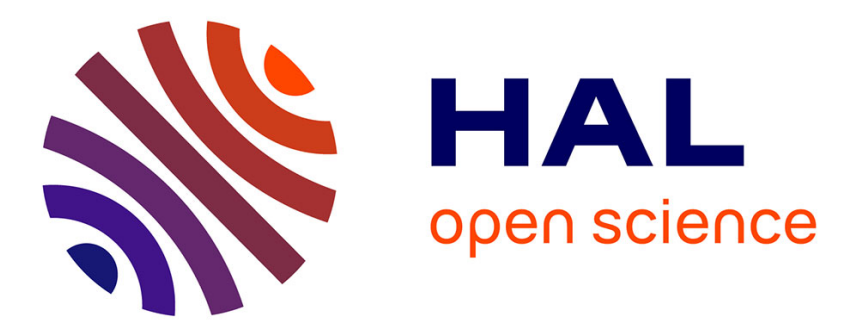

\title{
Recovery of forest structure and composition to harvesting in different strata of mixed even-aged central Appalachian hardwoods
}

Eric Zenner, Yvette Dickinson, Jerilynn Peck

\section{- To cite this version:}

Eric Zenner, Yvette Dickinson, Jerilynn Peck. Recovery of forest structure and composition to harvesting in different strata of mixed even-aged central Appalachian hardwoods. Annals of Forest Science, 2013, 70 (2), pp.151-159. 10.1007/s13595-012-0242-z . hal-01201462

HAL Id: hal-01201462

https://hal.science/hal-01201462

Submitted on 17 Sep 2015

HAL is a multi-disciplinary open access archive for the deposit and dissemination of scientific research documents, whether they are published or not. The documents may come from teaching and research institutions in France or abroad, or from public or private research centers.
L'archive ouverte pluridisciplinaire HAL, est destinée au dépôt et à la diffusion de documents scientifiques de niveau recherche, publiés ou non, émanant des établissements d'enseignement et de recherche français ou étrangers, des laboratoires publics ou privés. 


\title{
Recovery of forest structure and composition to harvesting in different strata of mixed even-aged central Appalachian hardwoods
}

\author{
Eric K. Zenner • Yvette L. Dickinson • JeriLynn E. Peck
}

Received: 4 May 2012 / Accepted: 23 August 2012 /Published online: 19 September 2012

(C) INRA / Springer-Verlag France 2012

\begin{abstract}
- Context Implementing nature-based silviculture requires understanding the structural and compositional changes that occur in forested stands under known disturbance types and intensities. - Aims The objectives were to assess the (a) resistance of hardwood forests to change, (b) their trajectory of recovery following disturbance, and (c) how closely resulting forests resemble original forests.

- Methods We characterized tree structure and composition at three points in time (pre-disturbance, 1-year post-disturbance, and $\sim 15$ years following disturbance) along a harvesting disturbance gradient created by removing trees in different forest canopy strata.

- Results Significant differences to pre-disturbance conditions were noted immediately post-harvest for tree basal area, density, species richness, and tree species composition; treatment differences were observed for all parameters except diversity. Plots exposed to the least extreme harvesting disturbances (cutting small and intermediate trees) had returned to pre-disturbance conditions for most parameters after 15 years, while the most extreme harvesting disturbance (cutting large trees) had not yet recovered.
\end{abstract}

Handling Editor: Gilbert Aussenac

Contribution of the co-authors EZ: concept, writing, facilitation YD: concept, collection, analyses, writing

JP: analyses, writing

Y. L. Dickinson • J. E. Peck

School of Forest Resources, The Pennsylvania State University,

117 Forest Resources Building,

University Park, PA 16802, USA

E. K. Zenner $(\bowtie)$

School of Forest Resources, The Pennsylvania State University,

305 Forest Resources Building,

University Park, PA 16802, USA

e-mail: eric.zenner@psu.edu
- Conclusions Although not initially resistant, Central Appalachian eastern hardwoods are fairly resilient to the removal of trees in the subcanopy or a mixture of the subcanopy and canopy; only the removal of solely canopy trees (i.e., high grading) and complete removal (i.e., clearcutting) appear to impose harvesting disturbances to which these forests may not be resilient.

Keywords Resistance $\cdot$ Recovery $\cdot$ Low thinning $\cdot$ High grading $\cdot$ Eastern hardwoods

\section{Introduction}

A primary theme in modern forest ecosystem management is "nature-based" silviculture in which management practices are used to emulate the outcomes of the natural disturbances to which forested ecosystems would be subjected in the absence of human intervention (Larsen and Nielsen 2007), under the presumption that these more "natural" disturbances are more likely to promote ecosystem resilience, particularly with respect to biodiversity (Seymour and Hunter 1999). Inherent to this approach is the need to understand how far management can deviate from the natural range of variability before compromising ecological integrity and resilience (Perry 1998). Doing so requires quantifying variability in the reaction to harvesting disturbances of known type and intensity by whatever ecosystem components are relevant to desired management objectives. The silvicultural technique of clearcutting represents a more intense form of disturbance than typically occurs naturally in the eastern and northern hardwood forests of North America (Lorimer 2001), which explains why it is often employed in this region to regenerate a different tree species composition than what would otherwise develop on a site. Other silvicultural techniques involving less intense disturbances have long 
been employed to achieve different objectives, such as regeneration or increased growth and quality (Miller and Baumgras 1994). Partial cutting approaches in particular are now also being recognized for their potential for more closely mimicking outcomes of natural disturbance (Franklin et al. 2007; Palik et al. 2002), which in this region are more frequently small-scale canopy gaps than stand replacement (Seymour et al. 2002).

Much of our understanding of the impacts of partial cutting comes from stratified uneven-aged stands of shadetolerant species, in which the resulting species composition is very similar to the initial species composition (Bédard and Majcen 2001; Bohn and Nyland 2003). In those stands, species composition varies relatively little with the portion of the diameter distribution (i.e., stratum) that is removed, although there may be other long-term consequences (e.g., dysgenics when harvesting only the largest trees, Hawley et al. 2005). In mixed even-aged stands, however, canopy dominants are often a different species from trees in lower strata due, at least in part, to differential shade tolerances (Oliver and Larson 1990). Removing only certain strata, therefore, may have significant implications for species composition. This is important for the hardwood forests of eastern North America, which are predominantly even-aged yet typically have reverse-J diameter distributions due to the differential shade tolerance of species in these mixed stratified forests (Oliver 1980a). A common misimpression in the region is that these stands are multi-aged, resulting in the tendency to cut the largest trees (diameter-limit harvesting or "high grading") as they are mistaken for older trees (Oliver 1980a). Because of species stratification, however, removal of the larger trees may have consequences for the species composition of the residual stands, and subsequently ramifications for the regeneration of future stands.

There is a surprising lack of information, however, on the impacts of most types of partial cutting in eastern North American hardwood forests, with the exception of a few growth and yield and regeneration studies following low thinning (e.g., Marquis and Ernst 1991; Ward 1992; Yanai et al. 1998). In addition to the lack of baseline information on which forest stand structures (other than tree density and basal area) are modified by different disturbance types and intensities, little information is available to guide expectations of how ecosystem conditions might respond to such disturbances, making informed management nearly impossible. To achieve the objective of maintaining ecosystem resilience (i.e., the ability of an ecosystem to resume function following a disturbance; Westman 1978), information is needed on at least three things: (1) the inherent resistance to change (i.e., which parameters remain unchanged); (2) their recovery trajectory (i.e., their rate of recovery following disturbance); and (3) the accuracy of the recovery (i.e., how closely the resulting forests resemble the original forests)
(Westman 1978). To complicate matters, resilience as a concept is predicated on ecosystem stability prior to disturbance (Connell and Sousa 1983), yet forests are dynamic systems perpetually changing through stages of stand dynamics and along successional pathways. Assessing change over time following disturbance, therefore, requires not only comparing pre- and post-disturbance conditions, but also disturbed and undisturbed (control) conditions.

The objectives of the current study, therefore, were to provide information on conditions necessary for ecosystem resilience by documenting which common forest stand parameters are modified by harvesting disturbances of different known type and intensity in order to (a) evaluate the resistance of hardwood forest stands to change by evaluating structural and compositional responses along a gradient of harvesting disturbance, (b) compare trajectories of recovery along this gradient, and (c) evaluate the accuracy of the resulting forests to pre-disturbance and undisturbed conditions. Our approach was to characterize tree structure and composition at three points in time (pre-disturbance, 1-year post-disturbance, and $\sim 15$ years following disturbance) along a gradient of harvesting disturbance created by cutting in different forest canopy strata.

\section{Material and methods}

\subsection{Study area and treatment design}

Three $~ 70$-year-old oak-mixed hardwood forest sites were chosen on public lands in central Pennsylvania (40 23'-39' $\left.\mathrm{N}, 7651-59^{\prime} \mathrm{W}\right)$. Although sites were allowed to vary in factors known to be less influential in our region (e.g., slope (5-70\%) and aspect (S-SE, W, N-NE) (Bowersox and Ward 1972), the most important biogeographical factors for our region, such as elevation $(160-320 \mathrm{~m})$ and soils (all stony and silty loams), were held generally comparable among sites. Prior to treatment, these were fully stocked (McGill et al. 1999) even-aged mixed stratified stands in the understory reinitation stage (Oliver 1980b) with predominantly reverse-J diameter distributions. Stands were dominated by yellow poplar (Liriodendron tulipifera L.), black oak (Quercus velutina Lam.), northern red oak (Quercus rubra L.), red maple (Acer rubrum L.), sugar maple (Acer saccharum Marsh.), sweet birch (Betula lenta L.), white oak (Quercus alba L.), scarlet oak (Quercus coccinea Münchh.), and American beech (Fagus grandifolia Ehrh.). Between 1993 and 1995, six cutting treatments were applied to adjacent 0.8 ha ( 2 acre) blocks at each site. Treatments spanned a gradient of disturbance (Fig. 1), from the least (1. uncut Control) to the greatest (6. Total removal of all stems) possible extreme. The degree of canopy strata removal increased approximately in this order, by cutting: 2. Low, 


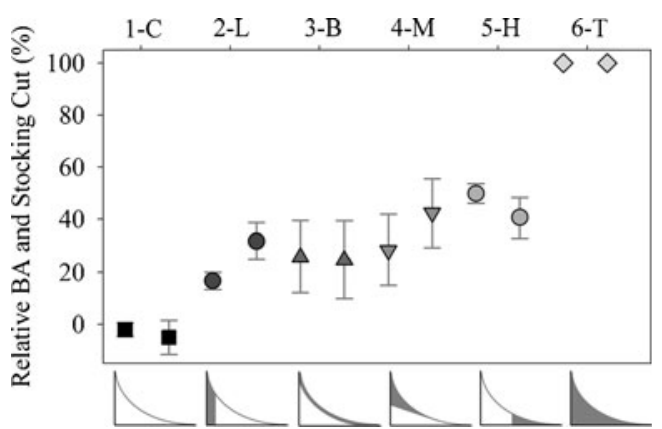

Fig. 1 Mean (error bars are std) relative basal area (left symbol for each treatment) and relative density (right symbol, stocking sensu McGill et al. 1999) removed (top) and an example of what portion of the diameter distribution was removed (bottom) in each treatment. $1=$ Control, $2=$ Low, $3=$ Broad, $4=$ Mid, $5=$ High, $6=$ Total. All stands had reverse-J diameter distributions prior to treatment

only the smallest trees; 3 . Broad, $2 / 3$ of the stocking from below and $1 / 3$ from above the median diameter (resulting in a fairly even cut across the diameter distribution); 4. Mid, suppressed, and intermediate trees; 5 . High, only the largest trees. Each treatment was replicated at all three sites, with the exception of the Mid treatment, which was only applied at two sites.

\subsection{Measurements and calculations}

Each block was composed of an interior 0.2 ha square measurement plot surrounded by a 20.1-m buffer of treated forest. Within each plot, all stems over $2.5 \mathrm{~cm}$ diameter at breast height (d.b.h) were inventoried for species and d.b.h. prior to cutting (Pre-cut), within a year after the treatment (Post-cut), and 14-16 years later (2009). The measured tree structural parameters included basal area (BA, square meter per hectare), stems per hectare (SPH), quadratic mean of the diameter at breast height (QMD, centimeter), the coefficient of variation of the diameter at breast height $\left(\mathrm{CV}_{\mathrm{DBH}}\right.$, centimeter), tree species richness, and Shannon's diversity index (Barnes et al. 1998, p. 586).

\subsection{Analyses}

The resistance of these stands to disturbance was evaluated by comparing Pre-cut and Post-cut structural parameters within each treatment type using the Kruskal-Wallis rank sum test in R 2.11.1 (R Development Core Team 2009) at the $\alpha=0.10$ level due to the small sample size. Pre-cut and Post-cut tree species composition for the partial cutting and control treatments was compared using distance-based MANOVA based on Sørensen distances while blocking by site and treatment (PerMANOVA in $P C-O R D$ v. 6, McCune and Meford 2011). Compositional redundancy (i.e., overlap in species composition) was based on these Sørensen distances and expressed as the inverse of Percent Dissimilarity
(Faith et al. 1987). Indicator species analysis (in $P C-O R D$ ) was also used to identify which tree species were significantly $(P<0.1)$ more frequent and abundant in the Pre-cut and Post-cut time periods.

The trajectory of recovery was compared among treatments along the disturbance gradient by ordinating tree species composition over time for each site separately using global nonmetric multidimensional scaling (NMS) on matrices of BA, relativized by species maxima, based on Sørensen distances (in $P C$-ORD). Each ordination was thus conducted on a matrix of a variable number of tree species (25-32) in five to six treatments (because the Mid treatment was unavailable at one site) across three time periods. In all three sites, scree plots indicated that two-dimensional solutions were most appropriate. After ensuring consistency of interpretation among several runs for each site, a statistically unique $(P<0.05)$ solution with final stress $\leq 13$ for each site was scaled proportionally on both axes. The $[x, y]$ coordinates for each of these three sets of scores were then averaged within each treatment type such that a single graph is presented reflecting the average positions in space of each treatment plot at each of the three points in time, which did not affect interpretation but simplified presentation. To evaluate the trajectory of recovery for relevant structural variables, a matrix of the seven variables that had Pearson correlations with the NMS axes of $r>0.4$ [tree density, QMD, standard deviation and coefficient of variation of $\mathrm{DBH}$, richness (of both tree species and size classes), and diversity (of both tree species and size classes)] were averaged across the three sites and ordinated using Principal Components Analysis based on a correlation cross-products matrix.

The accuracy of recovery was evaluated by comparing Pre-cut and 2009 structural parameters within each treatment type and by contrasting 2009 structural parameters among treatments using a Kruskal-Wallis rank sum test. Pre-cut and 2009 tree species composition of the partial cutting and control treatments were compared within each treatment type, and 2009 composition was contrasted among treatments, using PerMANOVA. In addition, the patterns of redundancy identified among the partial cutting and control treatments using NMS were compared using the Mantel Test, which calculates a Pearson correlation between square matrices (using Compare Scores in $P C-O R D$ ). Indicator species analysis was also used to identify which tree species were significantly more frequent and abundant in the Pre-cut and 2009 time periods.

\section{Results}

\subsection{Resistance}

Between the Pre-cut and Post-cut measurements (Fig. 1), the Control plots gained a small amount (averaging $1.4 \%$ ) of 
stocking while the remaining treatments lost stocking in the order of Low (24.1\%), Broad (27.4\%), High (36 \%), Mid (40 \%), and Total (100 \%) (McGill et al. 1999).

Significant changes between Pre-cut and Post-cut measurements were observed regardless of treatment for BA, SPH, richness, and diversity (rank sum test, all $P<0.01$, respectively) (Table 1). Although prior to cutting tree parameters did not differ among treatments (all $P>0.2$ ), following cutting, there were significant differences among treatments for all parameters (all $P<0.09)$ except diversity $(P=0.17)$.

Overstory composition differed between Pre-cut and Post-cut measurements (PerMANOVA, $P=0.06$ ), primarily due to the reduction in abundance of sweet birch, scarlet oak, and American beech following disturbance. Compositional redundancy, expressed as the inverse of percent dissimilarity among the same sample units Precut and Post-cut treatment, averaged $68 \%$, resulting in a standardized Mantel statistic of $r=0.81 \quad(P<0.001)$. Although tree composition did not differ among treatments either before $(P=0.83)$ or after the disturbance $(P=0.18)$, the average dissimilarity between Pre-cut and Post-cut plots decreased in the order of High (35\%; standard deviation, std $1 \%$ ), Mid (28\%; std $11 \%$ ), and Broad (17\%; std $9 \%$ ), and Low (17\%; std $8 \%$ ).

\subsection{Recovery trajectory}

Over the 15-year measurement period, the undisturbed Control plots had slight increases in BA and QMD, no change in SPH or diversity, and slight decreases in $\mathrm{CV}_{\mathrm{DBH}}$ and richness (Table 1). In all of the partially cut treatments, BA and SPH were initially reduced and then increased, returning to approximately Pre-cut levels (within one standard deviation) by 2009. The QMD increased in the Low and Mid plots before returning to Pre-cut levels, remained stable in the Broad plots, and initially declined in the High plots before returning to near Pre-cut levels by 2009 . The $\mathrm{CV}_{\mathrm{DBH}}$ initially decreased in the Low and High plots before returning to Pre-cut levels, remained stable with a slight increase over time in the Broad plots, and was initially stable and then increased substantially in the Mid plots. Whereas richness initially declined and then recovered to equal or exceed Pre-cut levels, diversity responded slightly and differentially among treatments initially but then stabilized at Pre-cut levels. In the most disturbed Total removal plots, after initial declines, both richness and diversity increased until at or above Pre-cut levels, SPH increased to nearly three times Pre-cut levels, and $\mathrm{BA}, \mathrm{QMD}$, and $\mathrm{CV}_{\mathrm{DBH}}$ all increased to approximately half of Pre-cut levels by 2009.

At all three sites, the most extreme changes are represented by the Control plots (Fig. 2), in which the dominant

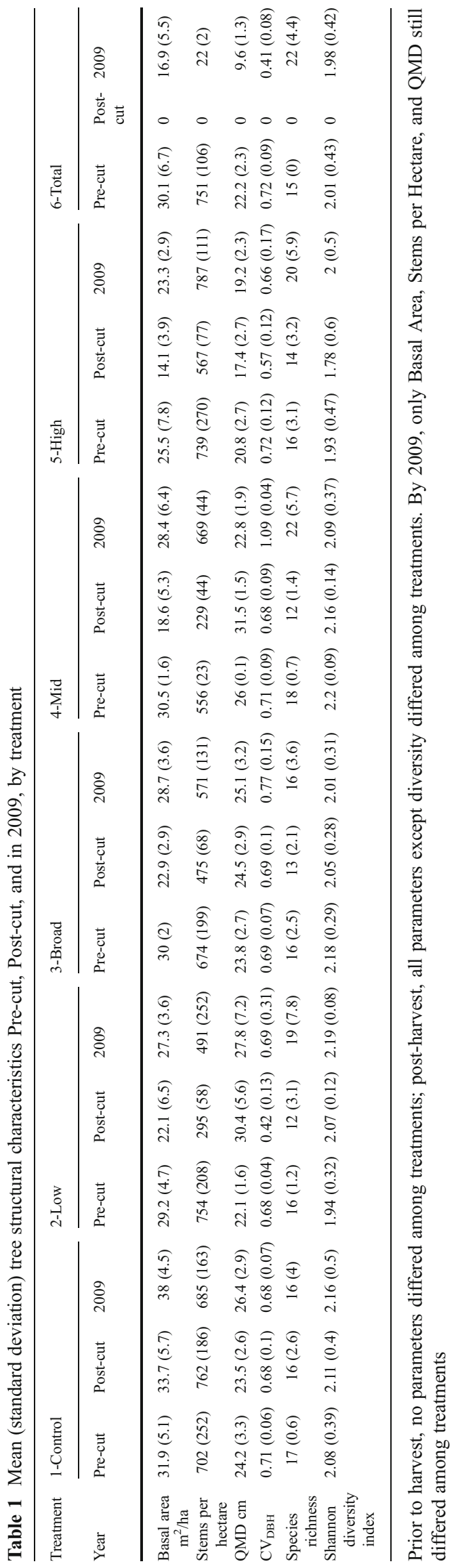




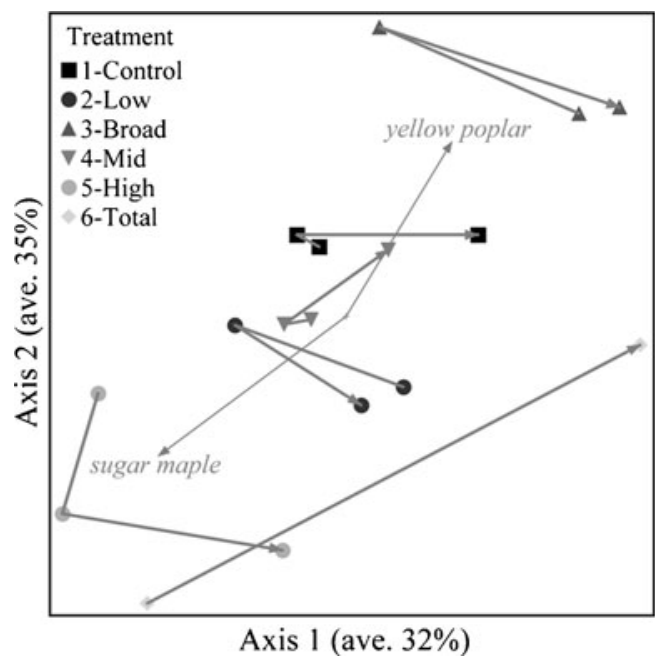

Fig. 2 Scatterplot showing the average position, across the three sites, of each treatment plot at three points in time in tree species basal area space characterized using NMS ordination with the Sørensen distance measure. Vectors begin at the Pre-cut composition, connect to the Postcut composition, and end (with arrow heads) at the 2009 composition. Vectors arising from the centroid show the directionality (angle) and magnitude (length) of associations of tree species with the ordination axes, indicating greatest abundances of sugar maple toward the High plots and greatest abundances of yellow poplar toward the Mid plots. The diagram has been rotated such that the compositional change in the control plots is aligned with Axis 1

and co-dominant trees at each site increased in influence over time (e.g., American beech and northern red oak in site 1 , yellow poplar and black oak in site 2, and yellow poplar and sugar maple in site 3 ), and the Total removal plots, which exhibited quite different trajectories from the Controls primarily as a result of an increase in influence by light demanding pioneer species such as yellow poplar and sweet birch across all sites. All four of the partially cut treatments changed trajectories over time. Initially, each shifted in composition as a result of the cut (from Pre-cut to Post-cut). The Low and Broad treatments then recovered, returning to near Pre-cut conditions (from Post-cut to 2009). In contrast, the Mid and High treatments only partially recovered between Post-cut and 2009, returning not to Pre-cut conditions but continuing to shift right along the Axis reflecting change in the Control plots. Although all partially cut treatments demonstrated some return toward Pre-cut composition (i.e., all trajectories contained acute angles), the High treatment developed a new trajectory quite distinct from that of the other partial cutting treatments. Ordering treatments from highest to lowest compositional change across the ordination space produced a ranking of 6-Total, 5-High, 2-Below, 4-Mid, 1Control, 3-Broad (Appendix).

Change in the structural composition paralleled that of the species composition in that the most extreme changes were represented by the Control and Total removal plots (Fig. 3), which occupied opposite ends of the first Axis.

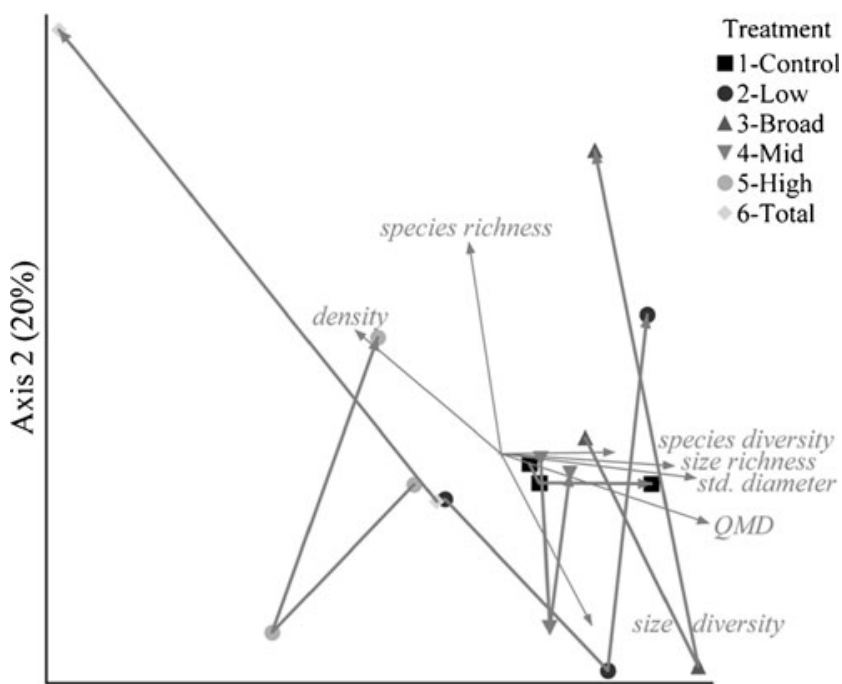

Axis $1(64 \%)$

Fig. 3 Scatterplot showing the position of each treatment type (averaged across the three sites) at three points in time in tree structure space characterized using PCA. Vectors begin at the Pre-cut composition, connect to the Post-cut composition, and end (with arrow heads) at the 2009 composition. Vectors arising from the centroid show the directionality (angle) and magnitude (length, scaled to $70 \%$ ) of associations of structural characteristics with the ordination axes. The diagram has been rotated such that the compositional change in the control plots is aligned with Axis 1

Further, once again, all four of the partially cut treatments reversed trajectories over time, initially shifting from Pre-cut to Post-cut (generally along Axis 2 with a reduction in species richness and an increase in size diversity) and then shifting back to a varying degree from Post-cut to 2009. Structurally, the greatest divergence from Pre-cut or Control conditions was seen for the Low treatment, although the Broad and High also established somewhat new trajectories. Ordering treatments from highest to lowest structural change across the ordination space produced a ranking of 6-Total, 5-High, 2-Below, 4-Mid, 1Control, 3-Broad, which is the same as was seen for species composition.

\subsection{Recovery accuracy}

Significant differences between Pre-cut and 2009 measurements were observed only for QMD and diversity (Kruskal-Wallis rank sum test, $P<0.06$ ) (Table 1). In comparison to the Control in 2009, all treatments except the Broad $(P=0.23)$ had significantly lower BA (all $P<$ $0.05)$; only the Total removal had significantly different (greater) SPH $(P<0.001)$; only the High and Total had significantly different (lower) QMD $(P=0.03$ and 0.01 , respectively); only the Mid and Total had significantly different (greater) $\mathrm{CV}_{\mathrm{DBH}}$ (both $P=0.01$ ); and no differences from the Control were observed in richness or 
diversity (all $P>0.14)$. In 2009, BA $(P=0.03)$, QMD $(P=$ $0.04)$, SPH $(P=0.07), \mathrm{CV}_{\mathrm{DBH}}(P=0.10)$, and richness $(P=0.10)$ still differed among treatments. Notably, the variation in tree sizes $\left(\mathrm{CV}_{\mathrm{DBH}}\right)$ was considerably higher in the Broad and particularly the Mid than in the Control, Low, High, or Total (Table 1). Despite the various treatments received, by 2009 , all plots were more than adequately stocked (65-109\%).

Pre-cut and 2009 tree species composition did not differ significantly (PerMANOVA, $P=0.23$ ), despite a continued greater frequency and abundance of sugar maple in the Precut time period. Compositional redundancy averaged $56 \%$, resulting in a standardized Mantel statistic of $r=0.75(P<$ $0.001)$. The average compositional dissimilarity between Pre-cut and 2009 plots remained higher for the High treatment ( $32 \%$; std $7 \%$ ) than for the other partial cutting treatments (all 21-22\%; std 8-12\%). The 2009 tree species composition differed significantly among treatments $(P=0.03)$ when controlling for site differences $(P<0.01)$, but no cutting treatment differed significantly from the Control (all $P>0.1$ ). On average across the three sites, the change in compositional dissimilarity between the Control and each partial cutting treatment was less than $\pm 5 \%$ (std $8-10 \%$ ) for all treatments except the High, which was $10 \%(9 \%)$; all cutting treatments, however, had more than $50 \%$ compositional similarity with both the Pre-cut and the Controls.

\section{Discussion}

If resistance is defined as a lack of response to a perturbation (cf. Westman 1978 among others), then no forest can ever be resistant to harvesting as tree densities and basal areas always decline. The intensity (e.g., the magnitude in the reduction in basal area) and type (e.g., strata cut) both affect stand structure (Oliver 1980b): whereas a diameter-limited thinning from below may remove only small trees, leaving the canopy intact, a diameter-limited cutting from above of equivalent intensity may remove much of the overstory while leaving the subcanopy intact. The general trend of the observed changes in many of the structural parameters immediately following harvest, and their differences among treatments, was therefore somewhat anticipated, if not previously documented. If, however, ecological resistance focuses on the impacts of harvest on parameters that measure conditions not changed by design (i.e., not specified in the silvicultural prescription), then the immediate impact of partial harvest on these stands involved a lack of resistance for richness, diversity, and species composition. Although the negative impacts of harvesting on richness and diversity can be grave in some ecosystems; in this region, harvesting tended to increase richness and diversity through the colonization of locally abundant native tree species. The most ecologically and silviculturally relevant result, therefore, may be the non-resistance of species composition and its long-term consequences, despite structural resilience (cf., Burton et al. 2009).

Compositional and structural development following very intense harvesting disturbances in North American hardwood forests has been characterized in an extensive literature of applied silvicultural research (Leopold and Parker 1985; Ross et al. 1986; Gilliam et al. 1995) and supports the generalized model of Oliver (1980b). After the extreme disturbance of clearcutting, the resulting stands are known to initially be composed of many small trees dominated by fast-growing species such as yellow poplar, red maple, or sweet birch (Elliott and Swank 1994; Beck and Hooper 1986; Arthur et al. 1997; Groninger and Long 2008), which is supported by our findings of increases in yellow poplar and sweet birch and lower QMD in the Total removal plots. Although high intensity disturbances are thought to cause greater ecosystem changes and reductions in resilience as compared to low intensity disturbances (Oliver 1980b; Halpern 1988; Frelich and Reich 1998), forest development after partial disturbance is otherwise poorly understood. Nonetheless, our results appear to support the brief model of succession following a partial disturbance presented by Oliver and Larson (1990), in which lesser disturbances can either maintain a single layered structure (e.g., our Low and Broad treatments) or result in multi-layered structures (e.g., Mid treatment) depending on the severity of the disturbance. Despite similar amounts of basal area removal in the Mid and High treatments (i.e., a similar disturbance intensity), our results for the coefficient of variation for tree diameters indicate that our High treatment did not develop a multi-layered structure, further supporting the assertion that intensity alone is insufficient to predict stand development following partial disturbance (cf., Oliver and Larson 1990). The divergence of these partial harvesting treatments may be explained by taking the stratum of disturbance into consideration. While the High treatment removed portions of the canopy, leaving subcanopy trees intact, the Mid treatment was more severe (sensu Chapin et al. 2002), removing trees both within and below the canopy.

The gradient in harvesting disturbance type was reflected in variation among treatments in resistance, recovery trajectories, and recovery accuracy. Pre-cut to Post-cut dissimilarity was nearly twice as great when cutting large trees (High) as opposed to cutting small trees (Low) or across the diameter distribution (Broad), and after 15 years dissimilarity to Pre-cut and Control 
conditions remained higher for the High treatment than for the other partial cutting treatments. Over the course of the 15 years following harvesting disturbance, many parameters, and especially species composition, were observed to shift in one direction immediately following the partial harvest treatments and then to shift in a different direction over the subsequent 14 years. The recovery trajectories for the Low and Broad treatments particularly demonstrated a strong return to Pre-cut condition, while the Mid and High treatments did not return to Pre-cut conditions but shifted more in parallel with the Control. In the end, the Low, Broad, and Mid partially harvested treatments eventually demonstrated considerable structural accuracy, in that a return to either Pre-cut (e.g., BA, SPH, $\mathrm{CV}_{\mathrm{DBH}}$ ) or Control (e.g., SPH, QMD) levels, within one standard deviation, was observed for most structural parameters. Further, although compositional redundancy and association were lower between Pre-cut and 2009 than Pre-cut and Postcut, richness, diversity and species composition no longer differed among partial harvest treatments or between 2009 and Control or Pre-cut-treatment levels. However, the lack of significant difference in diversity measures after 15 years may reflect more the tremendous landscape variability in the region (i.e., high site-to-site variability and large error terms) rather than resilience per se, as indicated by an even lower compositional redundancy in 2009 (56 \%) than immediately following cutting $(65 \%)$, particularly for the High treatment.

These findings indicate that some of the necessary (if not sufficient) conditions for ecosystem resilience may be able to be maintained in North American eastern hardwood forests despite, or perhaps through, some partial harvesting treatments. For example, partial harvesting targeting specific strata has been used to convert even-aged forests to uneven-aged by reducing overstory competition for light and thus improving conditions for shade intolerant regeneration (e.g., Schütz 2001). In even-aged mixed stratified forests such as these, small-diameter shadetolerant trees that persisted in the understory for decades (as evidenced by a reverse-J diameter distribution) could be released by such partial harvests. As demonstrated by the Mid treatment in this study, structural diversity (as measured by the coefficient of variation of tree diameters) at the stand level can also be increased using partial cutting, as has previously been noted for other forest types (Bauhus et al. 2009; O'Hara 1998; Zenner 2000; Gronewold et al. 2010). In this region, silvicultural techniques promoting multiple-layers, such as the Mid treatment in this study, may produce conditions more analogous to natural disturbances than techniques that do not result in such layers (Seymour et al. 2002).
It is possible, however, that the necessary conditions for ecosystem resilience may not be maintained following high grading, as reflected in our High treatment. Long known to be a poor silvicultural practice in eastern hardwoods (Nyland 1992), diameter-limited cutting from above (resulting in harvesting only large trees) may result in patchy and reduced regeneration and increased abundance of less desirable shade-tolerant species such as sugar maple and red maple (Fajvan 2006), reduced growth of desired residuals trees (Trimble 1971, Schuler 2004), and irregular yields with lower volume production (Nyland 2005). Our findings further indicate that high grading serves neither the development of two-cohort structures nor compositional recovery.

\section{Conclusion}

These North American eastern hardwood forests demonstrated poor initial resistance of both the structural parameters directly affected by cutting and indirectly affected measures of diversity and composition. By 15 years after the harvesting disturbance, however, these forests demonstrated recovery of most parameters for all but the High (high-grading) treatment, indicating the potential for applying partial harvesting treatments to achieve a variety of objectives while maintaining some of the necessary conditions for ecosystem resilience. These documented structural changes are in keeping with the model presented by Oliver and Larson (1990), which may provide a framework for using partial harvesting to direct stand structural development. Only the high-grading treatment was demonstrated to have little application for most silvicultural objectives.

Although a longer disturbance gradient, incorporating more gradations of higher severity disturbance, would be required to empirically characterize the presence or absence of resilience thresholds in this system (after Frelich and Reich 1998), this may not be necessary for the operational objective of identifying partial cutting techniques that may be suitable for mimicking the structural and compositional outcomes of natural disturbances. Rather, future studies should instead focus on monitoring specific, societally desired aspects of ecosystem integrity (e.g., wildlife habitat, water quality, recreational uses, etc.) and developing partial cutting regimes that maximize these responses.

Acknowledgements We thank J. Finley, S. Jones, J. Harding, J. Portzline, and D. Henry for data access and D. Heggenstaller for assistance with data collection. The manuscript was improved by the suggestions of three anonymous reviewers. This work was supported by the School of Forest Resources at The Pennsylvania State University. 


\section{Appendix}

Table 2 Distribution of relative basal area (BA, in percent) among major species groups Pre-cut, Post-cut, and in 2009 by site and by treatment type

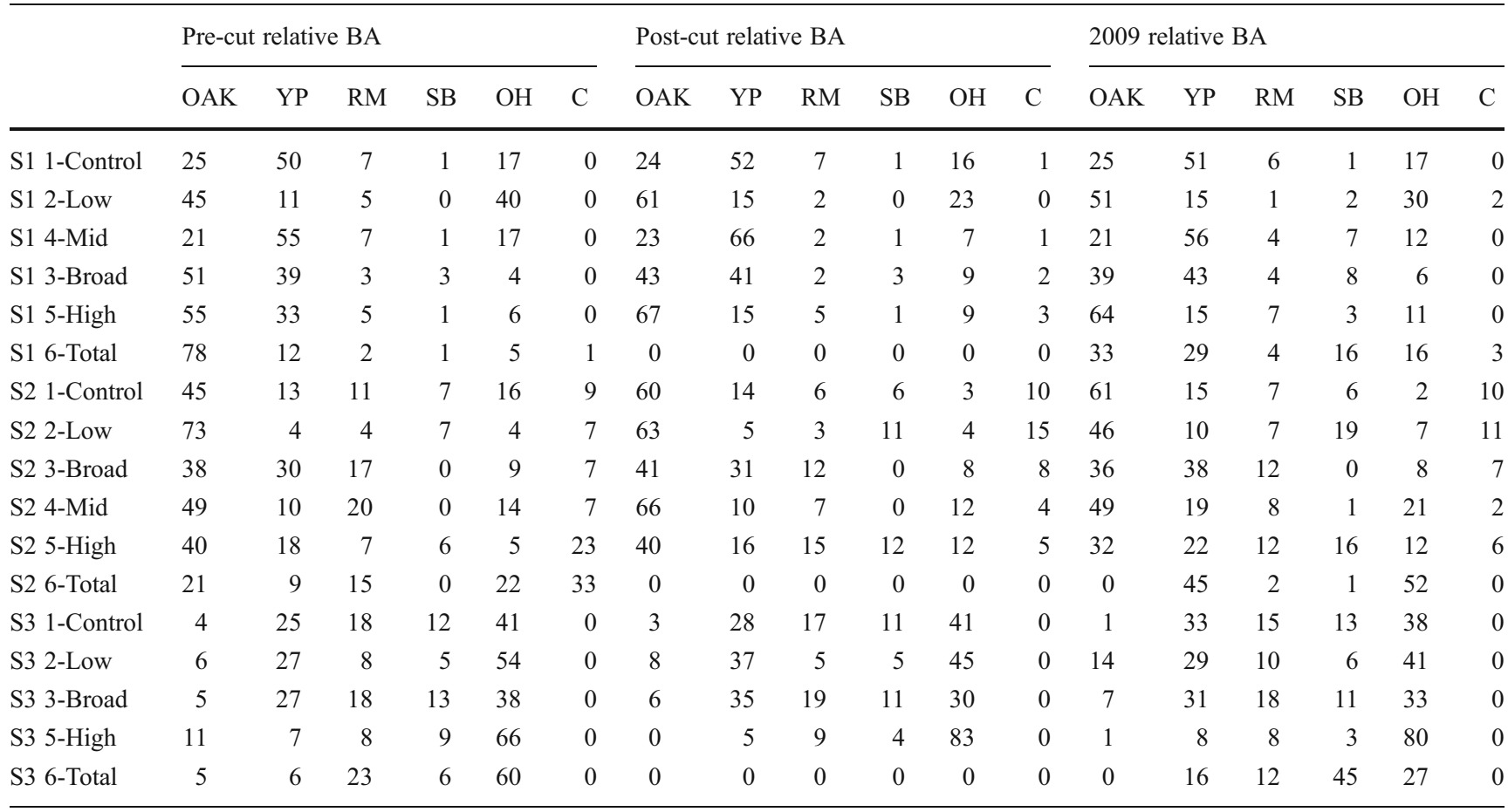

Species groups include all oak species, yellow poplar (YP), red maple (RM), sweet birch (SB), other hardwoods $(\mathrm{OH})$, and conifers $(\mathrm{C})$

\section{References}

Arthur MA, Muller RN, Costello S (1997) Species composition in a central hardwood forest in Kentucky 11 years after clear-cutting. Am Midl Nat 137:274-281

Barnes BV, Zak DR, Denton SR, Spurr SH (1998) Forest ecology. Wiley, New York

Bauhus J, Puettmann K, Messier C (2009) Silviculture for old-growth attributes. For Ecol Manage 258:525-537

Beck DE, Hooper RM (1986) Development of a Southern Appalachian hardwood stand after clearcutting. South J Appl For $10: 168-172$

Bédard S, Majcen Z (2001) Ten-year response of sugar maple-yellow birch-beech stands to selection cutting in Québec. North J Appl For 18:119-126

Bohn KK, Nyland RD (2003) Forecasting development of understory American beech after partial cutting in uneven-aged northern hardwood stands. For Ecol Manage 180:453-461

Bowersox TW, Ward WW (1972) Prediction of oak site index in the Ridge and Valley Region of Pennsylvania. For Sci 18:192-197

Burton JI, Zenner EK, Frelich LE, Cornett MW (2009) Patterns of plant community structure within and among primary and secondgrowth northern hardwood forest stands. For Ecol Manage 258:2556-2568

Chapin F, Matson P, Mooney H (2002) Principles of terrestrial ecosystem ecology. Springer Verlag, New York

Connell JH, Sousa WP (1983) On the evidence needed to judge ecological stability or persistence. Amer Nat 121:789-824
R Development Core Team, 2009. R: A language and environment for statistical computing. http://www.R-project.org.

Elliott KJ, Swank WT (1994) Changes in tree species diversity after successive clearcuts in the Southern Appalachians. Vegetatio 115:11-18

Faith DP, Minchin PR, Belbin L (1987) Compositional dissimilarity as a robust measure of ecological distance. Vegetatio 69:57-68

Fajvan MA (2006) Research on diameter-limit cutting in Central Appalachian forests. In: Proceedings of the conference on diameterlimit cutting in Northeastern Forests. USDA For. Serv. GTR NE342, Newtown Square, pp 32-28

Franklin JF, Mitchell RJ, Palik BJ (2007) Natural disturbance and stand development principles for ecological forestry. Gen. Tech. Rep. NRS-19, Newtown Square

Frelich LE, Reich PB (1998) Disturbance severity and threshold responses in the boreal forest. Cons Ecol 2:1-7

Gilliam FS, Turrill NL, Adams MB (1995) Herbaceous-layer and overstory species in clear-cut and mature Central Appalachian hardwood forests. Ecol Appl 5:947-955

Gronewold CA, D'Amato AW, Palik BJ (2010) The influence of cutting cycle and stocking level on the structure and composition of managed old-growth northern hardwoods. For Ecol Manage 259:1151-1160

Groninger JW, Long MA (2008) Oak ecosystem management considerations for Central Hardwoods stands arising from silvicultural clearcutting. North J Appl For 25:173-179

Halpern CB (1988) Early successional pathways and the resistance and resilience of forest communities. Ecology 69:1703-1715 
Hawley GJ, Schaberg PG, DeHayes DH, Brissette JC (2005) Silviculture alters the genetic structure of an eastern hemlock forest in Maine. Can J For Res 35:143-150

Larsen JB, Nielsen AB (2007) Nature-based forest managementWhere are we going?: elaborating forest development types in and with practice. For Ecol Manage 238:107-117

Leopold DJ, Parker GR (1985) Vegetation patterns on a Southern Appalachian watershed after successive clearcuts. Castanea $50: 164-186$

Lorimer CG (2001) Historical and ecological roles of disturbance in eastern North American forests: 9,000 years of change. Wildl Soc Bull 29:425-439

Marquis DA, Ernst RL (1991) The effects of stand structure after thinning on the growth of an Allegheny hardwood stand. For Sci 37:1182-1200

McCune B, Meford MJ (2011) PC-ORD. Multivariate analysis of ecological data, version 6. MjM Software, Gleneden Beach

McGill DW, Rogers R, Martin AJ, Johnson PS (1999) Measuring stocking in northern red oak stands in Wisconsin. North J Appl For 16:145-150

Miller GW, Baumgras JE (1994) Efficient silvicultural practices for eastern hardwood management. In: Opportunities for the hardwood industry to address environmental challenges; proceedings of the 22nd annual hardwood symposium of the Hardwood Research Council. Hardwood Research Council, Memphis, pp 2335

Nyland RD (1992) Exploitation and greed in Eastern Hardwood forests. J For 90:33-37

Nyland RD (2005) Diameter-limit cutting and silviculture: a comparison of long-term yields and values for uneven-aged sugar maple stands. North J Appl For 22:111-116

O'Hara K (1998) Silviculture for structural diversity, a new look at multiaged systems. J For 96:4-11

Oliver CD (1980a) Even-aged development of mixed-species stands. J For 78:201-203
Oliver CD (1980b) Forest development in North America following major disturbances. For Ecol Manage 3:153-168

Oliver C, Larson B (1990) Forest stand dynamics. McGraw-Hill, New York

Palik BJ, Mitchell RJ, Hiers JK (2002) Modeling silviculture after natural disturbance to sustain biodiversity in the longleaf pine (Pinus palustris) ecosystem: balancing complexity and implementation. For Ecol Manage 155:347-356

Perry DA (1998) The scientific basis of forestry. Ann Rev Ecol S29:435-466

Ross MS, Sharik TL, Smith DW (1986) Oak regeneration after clear felling in southwest Virginia. For Sci 32:157-169

Schuler TM (2004) Fifty years of partial harvesting in a mixed mesophytic forest: composition and productivity. Can J For Res 34:985-997

Schütz J-P (2001) Opportunities and strategies of transforming regular forests to irregular forests. For Ecol Manage 151:87-94

Seymour RS, Hunter ML Jr (1999) Principles of ecological forestry. In: Hunter ML Jr (ed) Composition in managing forests for biodiversity. Cambridge University Press, New York, pp 22-61

Seymour RS, White AS, deMaynadier PG (2002) Natural disturbance regimes in northeastern North America- evaluating silvicultural systems using natural scales and frequencies. For Ecol Manage 155:357-367

Trimble G (1971) Diameter-limit cutting in Appalachian hardwoods: boon or bane? USDA Forest Service RP-NE-208, Upper Darby

Ward JS (1992) Response of woody regeneration to thinning mature upland oak stands in Connecticut. USA For Ecol Manage 49:219-231

Westman WE (1978) Measuring the inertia and resilience of ecosystems. Bioscience 28:705-710

Yanai RD, Twery MJ, Stout SL (1998) Woody understory response to changes in overstory density: thinning in Allegheny hardwoods. For Eco Manage 102:45-60

Zenner EK (2000) Do residual trees increase structural complexity in Pacific Northwest coniferous forests? Ecol Appl 10:800-810 